\title{
KARAKTERISTIK LINGKUNGAN SONIK KAWASAN MASJID KERAJAAN DI SURAKARTA
}

\author{
Nur Rahmawati Syamsiyah \\ Program Studi Arsitektur, Fakultas Teknik, \\ Universitas Muhammadiyah Surakarta \\ nur_rahmawati@ums.ac.id \\ Rini Hidayati \\ Program Studi Arsitektur, Fakultas Teknik, \\ Universitas Muhammadiyah Surakarta \\ rh215@ums.ac.id
}

\author{
Dhani Mutiari \\ Program Studi Arsitektur, Fakultas Teknik, \\ Universitas Muhammadiyah Surakarta \\ dhani.mutiari@ums.ac.id

Wisnu Setiawan
Program Studi Arsitektur, Fakultas Teknik,
Universitas Muhammadiyah Surakarta
ws238@ums.ac.id

Naskah revisi akhir diterima pada: 27 September 2020

\section{Abstrak}

Masjid kerajaan di Surakarta yaitu Masjid Agung dan Masjid Al Wustho memiliki karakter kawasan yang berbeda. Kawasan Masjid Agung merupakan kawasan fungsi perdagangan yang ramai, sementara kawasan Masjid Al Wustho adalah kawasan fungsi pendidikan yang cenderung lebih tenang. Penelitian ini bertujuan untuk mengetahui karakteristik lingkungan sonik di kedua masjid, apakah fungsi kawasan berpengaruh terhadap lingkungan sonik yang terbentuk sesuai dengan karakter aktifitasnya. Penelitian dilakukan dengan pendekatan objektif melalui perekaman kondisi eksisting lingkungan sonik menggunakan H6Zoom dan analisis simulasi melalui program Audacity dan Surfer Mapping. Pendekatan subjektif dengan pengamatan aktivitas dan perilaku on-site survey serta wawancara. Hasil penelitian mengindikasikan karakter lingkungan sonik berbeda antara kedua masjid. Tingkat tekanan bunyi atau SPL rata-rata Masjid Agung adalah $60.8 \mathrm{~dB}$, lebih rendah dari Masjid Al Wustho yang memiliki nilai SPL $63.8 \mathrm{~dB}$. Fungsi kawasan tidak berpengaruh terhadap nilai SPL, melainkan komponen lanskap yang memiliki pengaruh. Penelitian ini dapat memberikan kontribusi terhadap perencanaan kawasan atau public space dengan pengurangan kebisingan lingkungan melalui pemilihan jenis material lanskap seperti pasir laut pantai selatan, vegetasi dan air serta perencanaan jalur sirkulasi yang terarah.

Kata-kata Kunci: Masjid, Komponen Lanskap, Lingkungan Sonik, Fungsi Kawasan

\section{SONIC ENVIRONMENTAL CHARACTERISTICS IN THE ROYAL MOSQUE IN SURAKARTA}

\begin{abstract}
The royal mosque in Surakarta, namely the Grand Mosque and the Al Wustho Mosque, has a distinctly urban character. The Grand Mosque area is a busy trade function area, while the Al Wustho Mosque area is an educational function area that tends to be quieter. This study aims to determine the characteristics of the sonic environment in the two mosques, whether the area's function affects the sonic environment which is formed according to the character of its activities. The research was conducted with an objective approach by recording the existing sonic environment conditions using H6Zoom and simulation analysis through the Audacity and Surfer Mapping programs., A subjective
\end{abstract}


approach by observing activities and behavior on-site surveys and interviews. The results indicated that the sonic environment character was different between the two mosques. The sound pressure level or SPL of the Great Mosque average is $60.8 \mathrm{~dB}$, lower than the Al Wustho Mosque, which has an SPL value of $63.8 \mathrm{~dB}$. The area's function does not affect the SPL value, but rather the landscape component that does. This research can contribute to area planning or public space be better by reducing environmental noise by selecting landscape material types such as south coast sea sand, vegetation, water, and directed circulation path planning.

Keywords: Mosque, Landscape Components, Sonic Environment, Function Area

\section{Pendahuluan}

Masjid adalah bangunan ibadah, sebagai salah satu bangunan umum yang sangat mengutamakan kenyamanan audial. Kenyamanan audial di dalam masjid dipengaruhi oleh bentuk rancangan geometri ruang dalam (Kurtruff, 2001), setting ruang dan penggunaan material finishing elemen ruang (Kurtruff, 2001; Lang, 1987). Kenyamanan audial di dalam ruang masjid dipengaruhi pula oleh kondisi lingkungan sonik di luar masjid. Eksisting masjid terutama eksisting kawasan masjid menjadi penting untuk diperhatikan agar kenyamanan audial tidak saja diperoleh di dalam masjid, namun juga di luar masjid.

Lingkungan sonik adalah kombinasi antara kondisi fisik dan bunyi yang terdengar, dan dipersepsikan, dialami atau dipahami manusia atau sekelompok orang dalam sebuah konteks. Lingkungan sonik kawasan masjid terutama dimulai dari luar tempat ibadah dapat memberikan suasana religi yang menenangkan terhadap emosi pengunjung (D.Zhang, 2016). Suara-suara yang muncul dalam sebuah kawasan akan membentuk lingkungan sonik yang dapat memberikan kesan tersendiri bagi pengunjung. Keberadaan lingkungan sekitar masjid atau kawasan masjid sangat beragam. Terutama masjid besar dalam skala kota atau kabupaten umumnya berada dalam kawasan yang ramai, agar mudah dikenali dan mudah diakses. Lingkungan sekitar masjid besar dapat berupa kawasan perdagangan, atau kawasan wisata/kebudayaan. Lingkungan sonik yang terbentuk di kawasan tersebut tentunya berupa suara majemuk, dengan kekuatan suara yang beragam.

Penelitian ini mengambil dua masjid besar di Surakarta, yang masuk dalam kategori masjid kerajaan, sebagai cagar budaya, yaitu Masjid Gedhe Surakarta atau Masjid Agung dan Masjid Al Wustho (lihat Gambar 1). Kedua masjid berada dalam kawasan yang berbeda. Masjid Agung ada di kawasan perdagangan (dekat pasar Klewer, pasar cinderamata, Pusat Grosir Solo dan Beteng Trade Center), kawasan wisata budaya (Kraton Kasunanan Surakarta Hadiningrat) dan kawasan pendidikan (MA Mambaul'Ulum) dan masih masuk dalam struktur tata ruang pemerintahan kerajaan MataramIslam di Jawa. Sementara itu Masjid Al Wustho berada di kawasan pendidikan (SD Muhammadiyah 1, SD Ketelan 12, TK Bustanul Athfal, SMA Muhammadiyah 1, SMP Negeri 10, SMP Negeri 5) dan kebudayaan/wisata (Istana Mangkunegaran). Kedua masjid kerajaan ini sangat penting diteliti, sebab aspek akustik atau bunyi yang akan memberikan kesan lingkungan kawasan masjid tersebut. Lingkungan sonik dari suatu kawasan yang berbeda dapat dirasakan sebagai suatu kesan dan makna yang berbeda-beda pula bagi pendengarnya. Pengaruh setiap sumber suara yang muncul di kawasan/lokasi penelitian tidak dapat diabaikan, karena dapat membentuk persepsi pengunjung sebagai aspek subjektivitas pendengar untuk dipertahankannya keadaan sonik yang memberikan kenyamanan. 


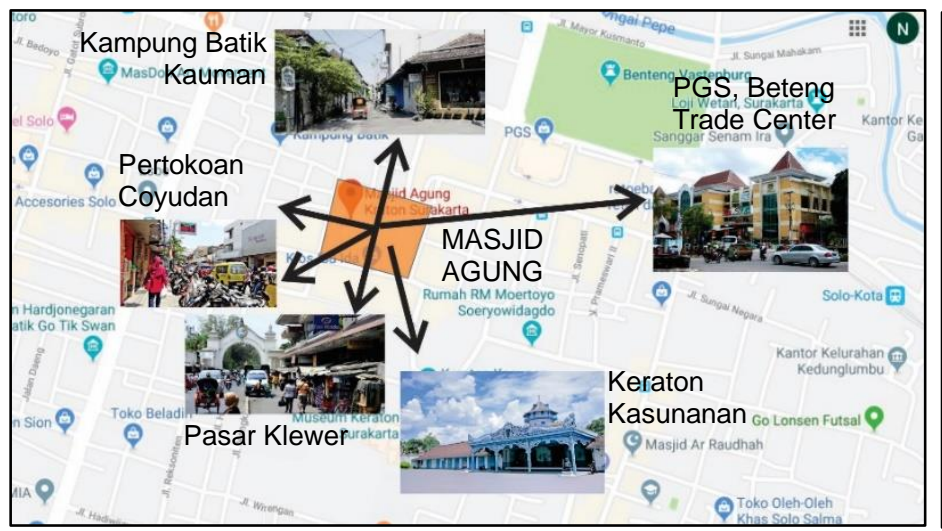

(a)

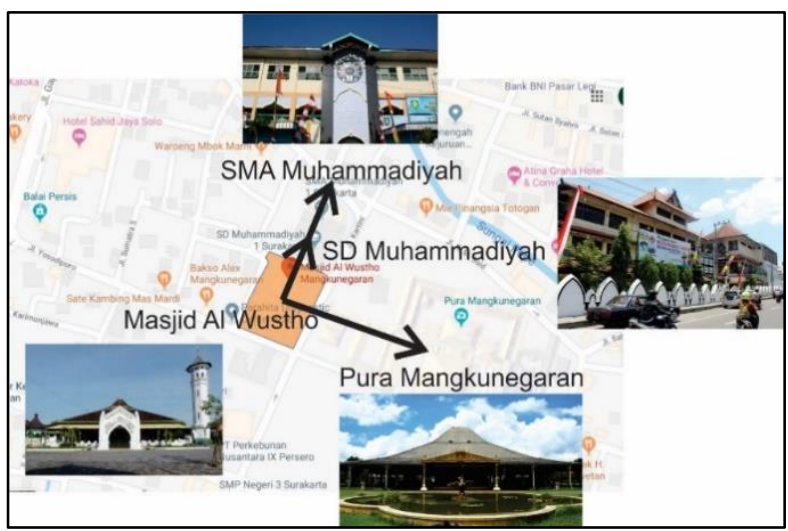

(b)

Gambar 1. Lokasi Penelitian (a) Masjid Agung Surakarta Dan (b) Masjid Al Wustho Sumber: Dokumen Peneliti, 2020

Untuk menjawab tantangan dalam kemajuan penelitian lingkungan sonik di suatu kawasan, digunakan konsep sistematis untuk lebih memahami pengalaman akustik seseorang melalui pendekatan terhadap komposisi sumber suara, persepsi pendengar dan konteks di balik suara, yang disebut dengan soundscape (Miller, 2013). Soundscape adalah komponen akustik lingkungan yang dapat dirasakan oleh manusia, merupakan kombinasi suara yang membentuk lingkungan atau muncul dari lingkungan, sesuai IS0 12931-1-2014. Soundscape menitik beratkan pada kualitas persepsi kenyamanan kawasan, yang mempengaruhi kesan psikologis, berdasar pada ruang dan waktu. Soundscape dipengaruhi pula oleh kualitas suara alam dan buatan, bising lingkungan, dan kondisi fisik landskap (Schafer, 1969; Kang, 2010). Memaknai kawasan masjid melalui bunyi dapat dilakukan dengan metode soundscape, karena bunyi merupakan mediator antara manusia dengan lingkungan (Fowler, 2013). Soundscape membuat seseorang akan lebih memahami suatu places, dari bunyi yang dihasilkan di dalamnya, yaitu bunyi alami dan tidak dibuat-buat. Masjid dan lingkungan sekitarnya pada masa lalu tentunya lebih terasa nilai kesakralannya, karena belum terdapat kebisingan kendaraan bermesin seperti sekarang.

Begitu pentingnya kondisi lingkungan sonik di sebuah kawasan masjid, sehingga penelitian ini bertujuan untuk mengetahui seberapa besar pengaruh suara lingkungan saat ini terhadap pembentukan karakteristik lingkungan sonik, hingga teridentifikasi komponen lanskap kawasan yang menjadi penyebab terbentuknya karakteristik tersebut. Penelitian ini memerlukan pengukuran secara objektif yaitu mengukur SPL atau sound presure level (tingkat tekanan bunyi), pengamatan, perekaman suara serta dianalisis bersamaan dengan pengukuran subyektif terhadap pengunjung, pengamatan perilaku, aktivitas, dan komponen fisik landskap masjid, dengan tetap memperhatikan aspek sejarah yang tervisualisasi secara fisik dalam lingkup meso atau kawasan dan makro atau urban.

\section{Metode}

Penelitian ini menggunakan metode kombinasi (mixed method) yaitu metode kuantitatif dan kualitatif, yang digunakan bersama-sama dalam satu penelitian, sehingga diperoleh data yang lebih lengkap dan menyeluruh. Sugiyono (2012) mengatakan kelebihan mixed method adalah data lebih komprehensif, valid, reliable dan obyektif dengan hasil penelitian dan memiliki nilai kebenaran. Data kualitatif dan kuantitatif dileburkan secara berimbang (concurrent triangulasi). Data kualitatif menjadi penerjemah (interpretasi) atau pemakna dari data kuantitatif (Creswell, 2007).

Metode kuantitatif digunakan untuk pendataan dan penganalisaan pengukuran soundscape (SPL), sedangkan metode kualitatif digunakan untuk studi literature, observasi aspek lanskap, aktivitas, sejarah dan urban serta wawancara lepas. Keseluruhan data didiskusikan atau proses iterasi hingga memperoleh hasil yang akurat sebagaimana dalam Gambar 2. 


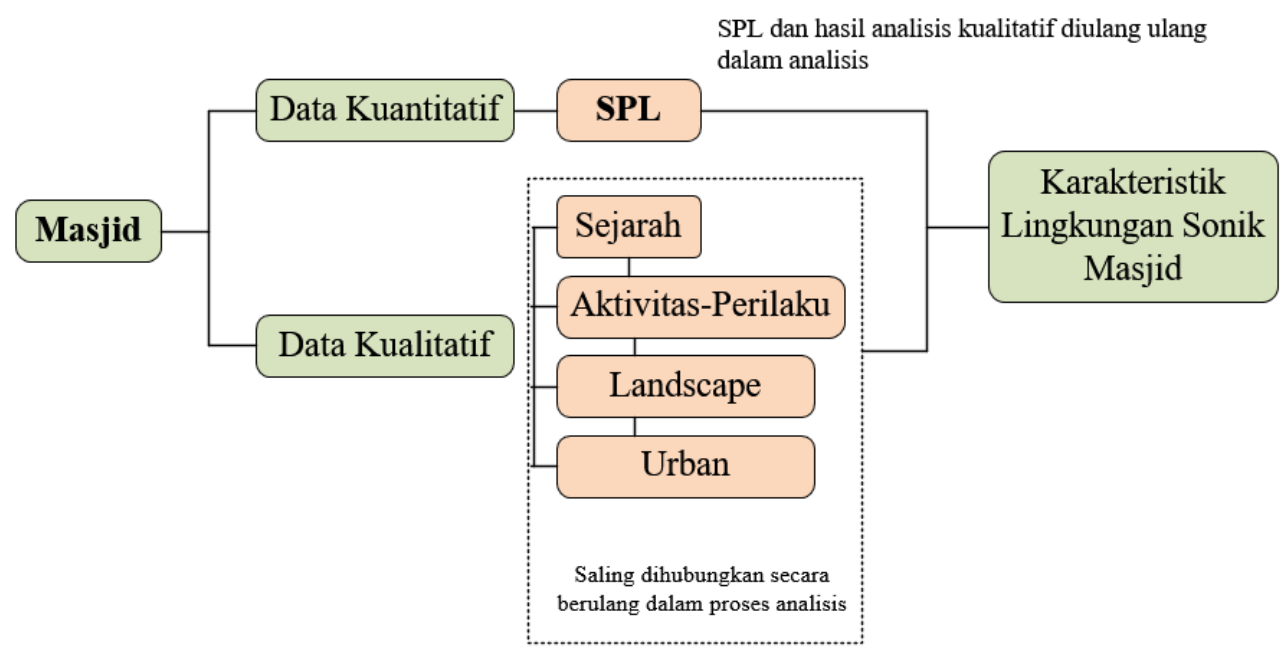

Gambar 2. Proses Iterasi Dalam Metode Penelitian Ini Sumber: Dokumen Peneliti, 2020

Prosedur penelitian diawali dengan: 1] menentukan letak titik ukur di lokasi penelitian dengan pola grid agar merata di seluruh kawasan masjid. Jarak antar titik ukur 2-6 meter tergantung lokasi, 2] kesiapan alat ukur berupa: alat ukur perekam bunyi (satuan desibel) H6Zoom handy recorder yang terpasang di tripod (Gambar 3), thermohygrometer untuk mengukur suhu dan kelembaban udara dan alat ukur anemometer untuk mengukur kecepatan angin. Seluruh alat digunakan bersamaan agar keadaan iklim mikro terekam, karena kualitas gelombang energy bunyi dipengaruhi oleh kondisi iklim setempat (Mediastika, 2005). Alat perekam diletakkan pada ketinggian 1.5 meter dengan jarak ideal sekitar 1 meter dari pengamat/peneliti. Pengambilan data objektif setiap titik dilakukan selama kurang lebih 1 menit dengan pendekatan five second method. Bersamaan dengan perekaman suara, dilakukan pula pencatatan kejadian yang teridentifikasi dari bunyi yang paling dominan terdengar dari alat H6Zoom. Data pengukuran SPL dimasukkan dalam software Audacity lalu disimulasikan dengan software Surfer Mapping. Proses pengambilan data terskemakan sebagaimana Gambar 3.
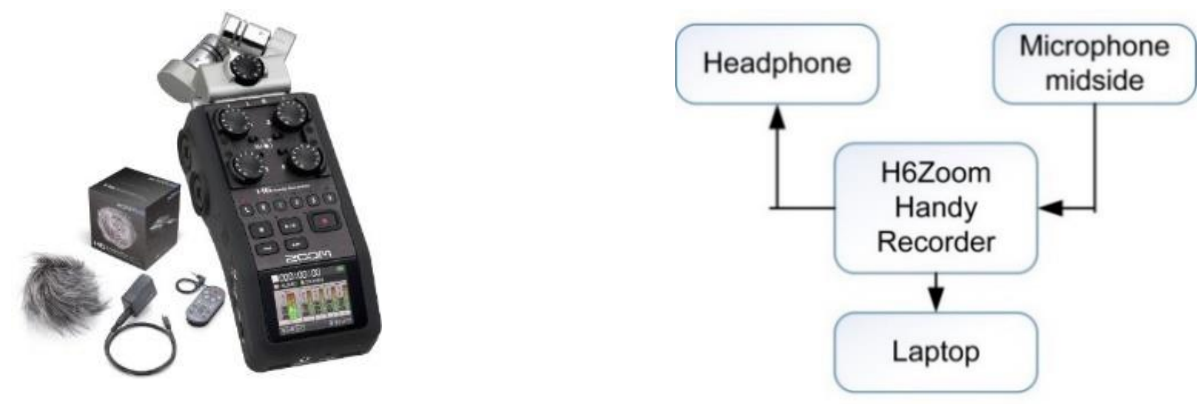
Gambar 3. (Kiri) H6Zoom Handy Recorder Alat Utama; (Kanan) Skema Rangkaian Pengambilan Data Akustik
Sumber: Dokumen Peneliti, 2019, Skema Adaptasi Dari Damaranti (2017)

Pengambilan data di kedua masjid dilakukan pada pagi hingga sore hari, dengan reading time tiap titik ukur selama 1 menit. Data kuantitatif berupa nilai kuat tekanan bunyi (SPL). Data bersifat kualitatif diskriptif berupa hasil wawancara dan pengamatan terhadap pengguna dan setting fisik lingkungan masjid. Data kuantiatif terbentuk dipengaruhi oleh setting fisik lingkungan masjid, sementara data kualitatif diperoleh dari persepsi pengunjung terhadap lingkungan sonik yang terbentuk karena adanya setting fisik. Data kuantitatif yang tepat harus berdasar letak titik ukur yang terdapat di halaman luar masjid. Data kuantitatif SPL ditindaklanjuti dengan simulasi menggunakan program 
Surfer Mapping versi 11, untuk melihat distribusi suara yang terbentuk. Pengambilan data kuantitatif sebagaimana ada di Gambar 4.
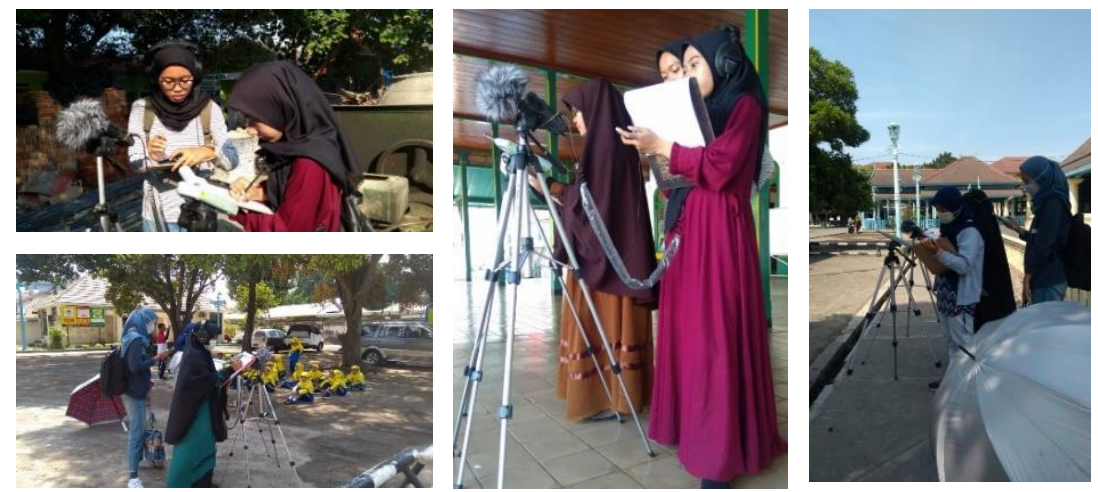

Gambar 4. Rangkaian Pengambilan Data Akustik Di Masjid Al Wusho

Dan Masjid Agung Surakarta

Sumber: Dokumentasi Peneliti, 2019

\section{Hasil dan Pembahasan}

\section{Sejarah dan Perkembangan Kawasan Masjid}

Masjid Agung Surakarta berdiri pada masa Paku Buwono II. Awalnya hanya berupa pendopo dengan tiang kayu, pindahan dari Keraton Kartasura. Masjid ditempatkan secara makro dalam tata ruang Kota Mataram Islam. Masjid Agung berada di sebelah barat alun-alun, dan alun-alun berada di sebelah utara keraton. Pola ruang Kota Mataram Islam dilengkapi dengan adanya Pasar Gedhe yang berada di belahan utara alun-alun. Pada masa pemerintahan Paku Buwono III tahun 1788, masjid selesai dibangun seperti yang ada saat ini. Masjid berdiri di atas tanah seluas $19.180 \mathrm{~m}^{2}$, dikelilingi pagar tembok setinggi $3.25 \mathrm{~m}$. Luas halaman bagian depan masjid adalah $7.644 \mathrm{~m}^{2}$ dengan beberapa bangunan pendopo terbuka berdiri di atas halaman masjid, ada istal (kandang kuda), tempat kereta raja dan bangsal pradangga untuk upacara adat. Seiring berjalan waktu bangunan pendopo itu berubah fungsi dan berubah bentuk. Bentuk menjadi tertutup dan fungsi istal menjadi bangunan untuk Tata Usaha dan keamanan masjid, tempat kereta raja menjadi bangunan untuk takmir masjid. Hanya bangsal pradangga yang masih berbentuk pendopo terbuka (El-Qudsy, et al., 2014).

Perubahan bentuk bangunan seiring dengan kebutuhan akan pemeliharaan dan perawatan masjid, mengingat kawasan sekitar masjid pun mengalami perubahan akibat perkembangan perekonomian. Dahulu tata wilayah sakral sekitar masjid masih terjaga, karena Pasar Gede terletak di utara masjid dengan jarak 980m dari masjid, namun sekarang nilai kesakralan mengalami pergeseran, karena perubahan lingkungan yang begitu pesat. Terdapat banyak pasar tekstil sekitar masjid, Pasar Klewer dan pasar cinderamata yang berjarak hanya $60 \mathrm{~m}$ dari masjid, Benteng Trade Center (BTC) dan Pusat Grosir Solo (PGS) berjarak 430 m dari masjid. Sejak berdirinya BTC tahun 1992 dan PGS tahun 2000, menjadikan kawasan masjid ramai dan menjadi kawasan yang sibuk.

Berbeda dengan Masjid Agung Surakarta, Masjid Al Wustho tidak mengalami perubahan berarti dalam tata wilayah sakral. Masjid yang ada sekarang adalah hasil pemugaran pada masa Mangkunegara VII tahun 1878. Awalnya masjid diperuntukkan bagi keluarga raja, namun sejak tahun 1924 berfungsi juga untuk umum, terutama untuk menunjang pendidikan Islam dari Yayasan Muhammadiyah. Tahun 1935 berdiri bangunan pendidikan di sekitar masjid, dan hingga sekarang masih tetap eksis. Beberapa bangunan pendidikan seperti TK Bustanul Athfal masih berada di tapak masjid, SD Muhammadiyah 1 berjarak $50 \mathrm{~m}$ dari masjid, SMA Muhammadiyah 1 berjarak $120 \mathrm{~m}, \mathrm{SD}$ Ketelan 12 berjarak 70 m, SMP Negeri 3, SMP Negeri 10 berjarak 260 m dan Gedung Pusat Majelis Tafsir Al Qur'an berjarak $350 \mathrm{~m}$ dari Masjid Al Wustho. 
Perubahan fungsi dari masjid yang bersifat privat ke masjid yang bersifat publik, ternyata tidak menjadikan masjid seperti bagian dari kota yang sibuk dan ramai. Perkembangan kawasan sekitar masjid tidak berpengaruh signifikan terhadap karakteristik lingkungan sonik masjid.

\section{Aktivitas dan Tata Lanskap Kawasan Masjid}

Lanskap Masjid Agung Surakarta merupakan elemen perancangan yang tidak pernah luput dari pemaknaan dan pengalaman ruang sang umat, termasuk dalam menawarkan suatu sequence-sequence yang menggiring kepada kekhusyukan (Feby Hendola, 2018). Diawali saat berada di pintu gerbang halaman masjid, berjalan memasuki halaman masjid, melepas alas kaki, dan berwudhu, menaiki tangga menuju serambi lalu menaiki tangga lagi untuk memasuki ruang utama masjid. Masjid kerajaan merupakan masjid tradisional, terdapat hirarki lantai, sejak pelataran, serambi/teras, hingga ruang utama. Hierarki menandakan tingkat kesucian dari ruang tersebut.

Pola aktivitas dan perilaku pengunjung masjid dapat terbentuk karena pengaruh komponen lanskap, yang berupa jalur pejalan kaki, hamparan pasir dan vegetasi. Jalur pejalan kaki berupa paving. Hamparan pasir pantai selatan yang diatasnya tumbuh beberapa jenis tanaman peneduh. Hasil pengamatan menemukan bahwa tidak semua pengunjung memasuki halaman masjid untuk tujuan sholat, melainkan hanya sekedar lewat. Pergerakan pengunjung antara dua kawasan perekonomian yang penting di Surakarta, PGS dan BTC di utara masjid dan Pasar Klewer di selatan masjid, membentuk pola yang lebih bebas, tidak terarah (lihat Gambar 5). Pengunjung yang hanya sekedar lewat tidak mengikuti jalur pejalan kaki yang telah disediakan. Pengunjung lebih memilih berjalan di atas pasir, karena lebih teduh dinaungi pohon rindang, sementara jalur pejalan kaki tidak. Sementara itu pergerakan pengunjung yang memasuki halaman Masjid Al Wustho cenderung tidak terarah, disebabkan halaman tidak memiliki jalur pedestrian. Pengunjung dengan berjalan kaki ataupun dengan berkendaraan motor melalui jalur yang sama. Halaman masjid berfungsi sebagai area parkir mobil dan motor, sekaligus berfungsi untuk pejalan kaki.

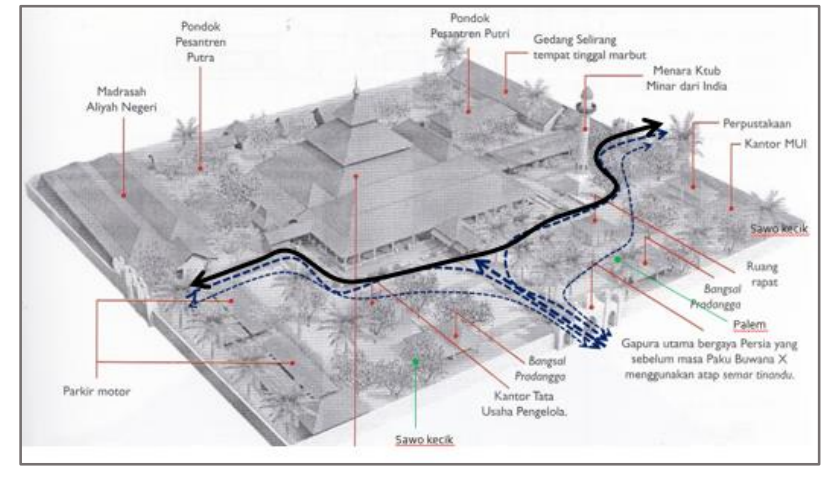

(a)

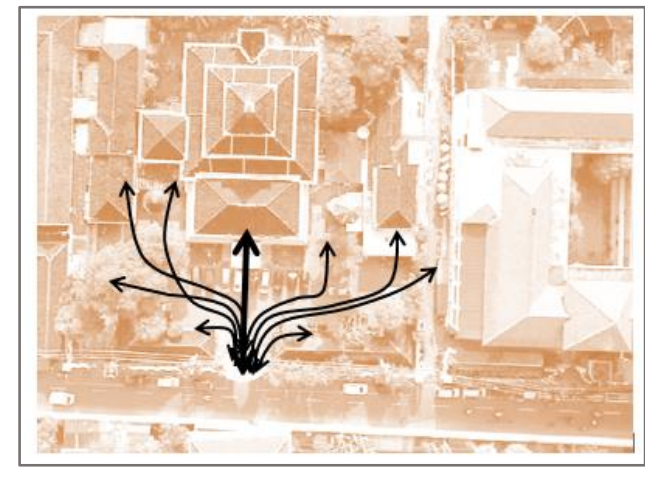

(b)

Gambar 5. Pola Pergerakan Aktivitas Pengunjung Di Halaman Masjid (a) Masjid Agung Surakarta, Dan (b) Masjid Al Wustho

Sumber: Analisis Peneliti, 2019

\section{Urban Soundscape Kawasan Masjid}

Nilai rata-rata SPL Masjid Agung Surakarta sebesar 60.8 dB dan Masjid Al Wustho 63,8 dB. Keduanya masuk dalam kategori tidak bising, karena ada di bawah batas kebisingan 70 dB (Egan, 1988). Selisih nilai $3.0 \mathrm{~dB}$ merupakan batas minimal perbedaan bunyi dapat didengar signifikan (Egan, 1988). Simulasi pemetaan nilai SPL memperlihatkan bahwa pekarangan/halaman masjid Agung seluas $7.644 \mathrm{~m} 2$ memiliki distribusi bunyi yang merata (Gambar 6). Interferensi gelombang terjadi dekat pintu masuk serambi dan di dekat menara. Interferensi penguatan bunyi di dekat menara disebabkan tempat itu digunakan secara rutin untuk berolah raga bagi siswa SD Kauman, sehingga menghasilkan 
suara pluit, suara teriakan anak anak, suara tendangan bola dan sebagainya. Sedangkan penguatan bunyi di dekat pintu masuk serambi adalah gesekan sepatu/langkah kaki orang dewasa yang melintas di dekat serambi atau suara pengunjung yang meletakkan alas kakinya sebelum memasuki serambi.

Nilai SPL tertinggi mencapai $101.37 \mathrm{~dB}$, yang merupakan suara bising dari lalu lintas dan bunyi troli pedagang yang melintas di halaman masjid. Sekalipun mencapai angka maksimal, namun lingkungan sonik masjid masuk kategori tidak bising (rata-rata SPL 60,8 dB). Komponen lanskap berperan dalam pembentukan karakter lingkungan sonik tidak bising (Rehan, 2016). Komponen lanskap yang paling pegang peran adalah hamparan pasir pantai selatan, yang dapat menyerap bunyi. Penelitian Kurniawan \& Isranuri (2016) bahwa pasir pantai selatan memiliki sifat menyerap bunyi. Kemampuan menyerap bunyi disebabkan pasir pantai selatan mengandung magnesium $(\mathrm{Mg})$ dan bijih besi (Fe) (Lusiyana, Toifur, \& Rohman, 2014), di mana kedua zat ini bersifat menyerap bunyi. Magnesium berasal dari garam laut. Kesimpulan ini diperkuat oleh data kecepatan angin selama waktu pengukuran $0,0-0,3 \mathrm{~m} /$ detik, atau bisa dikatakan tidak ada pergerakan udara sama sekali yang dapat membawa bunyi keluar dari kawasan masjid. Hal ini memperkuat analisis bahwa suara diserap oleh pasir, bukan terbawa oleh angin. Pasir sebagai pereduksi bunyi, dan mampu menyerap bunyi bising yang disebabkan aktivitas pengunjung (termasuk pedagang) yang lalu lalang di halaman masjid dan anak-anak sekolah yang setiap hari berolah raga di halaman pasir masjid. Nilai SPL dapat dilihat dalam Tabel 1 dan hasil simulasi dapat dilihat dalam Gambar 6.

Tabel 1. Nilai SPL Masjid Agung Surakarta

\begin{tabular}{cccccccc}
\hline Titik Ukur & $\begin{array}{c}\text { SPL } \\
(\mathbf{d e c i b e l )}\end{array}$ & Titik Ukur & $\begin{array}{c}\text { SPL } \\
\text { (decibel) }\end{array}$ & Titik Ukur & $\begin{array}{c}\text { SPL } \\
\text { (decibel) }\end{array}$ & Titik Ukur & $\begin{array}{c}\text { SPL } \\
(\mathbf{d e c i b e l )}\end{array}$ \\
\hline 1 & 52.86 & 14 & 56.8 & 27 & 50.98 & 40 & 91.86 \\
\hline 2 & 49.92 & 15 & 68.04 & 28 & 52.37 & 41 & 57.4 \\
\hline 3 & 49.65 & 16 & 57.85 & 29 & 52.69 & 42 & 66.35 \\
\hline 4 & 53.04 & 17 & 54.29 & 30 & 49.8 & 43 & 61.08 \\
\hline 5 & 56.07 & 18 & 56.6 & 31 & 52.19 & 44 & 56.53 \\
\hline 6 & 52.48 & 19 & 55.85 & 32 & 59.66 & 45 & 58.72 \\
\hline 7 & 50.95 & 20 & 54.86 & 33 & 55.13 & 46 & 58.77 \\
\hline 8 & 54.26 & 21 & 55.24 & 34 & 73.19 & 47 & 56.47 \\
\hline 9 & 51.54 & 22 & 55.72 & 35 & 81.61 & 48 & 57.56 \\
\hline 10 & 51.97 & 23 & 57.1 & 36 & 101.37 & 49 & 62.16 \\
\hline 11 & 56.74 & 24 & 58.3 & 37 & 87.68 & 50 & 60.28 \\
\hline 12 & 73.72 & 25 & 55.08 & 38 & 86.83 & 51 & 63.37 \\
\hline 13 & 66.01 & 26 & 52.1 & 39 & 93.74 & 52 & 58.01 \\
\hline
\end{tabular}

Sumber: Data Pengukuran Lapangan, 2019

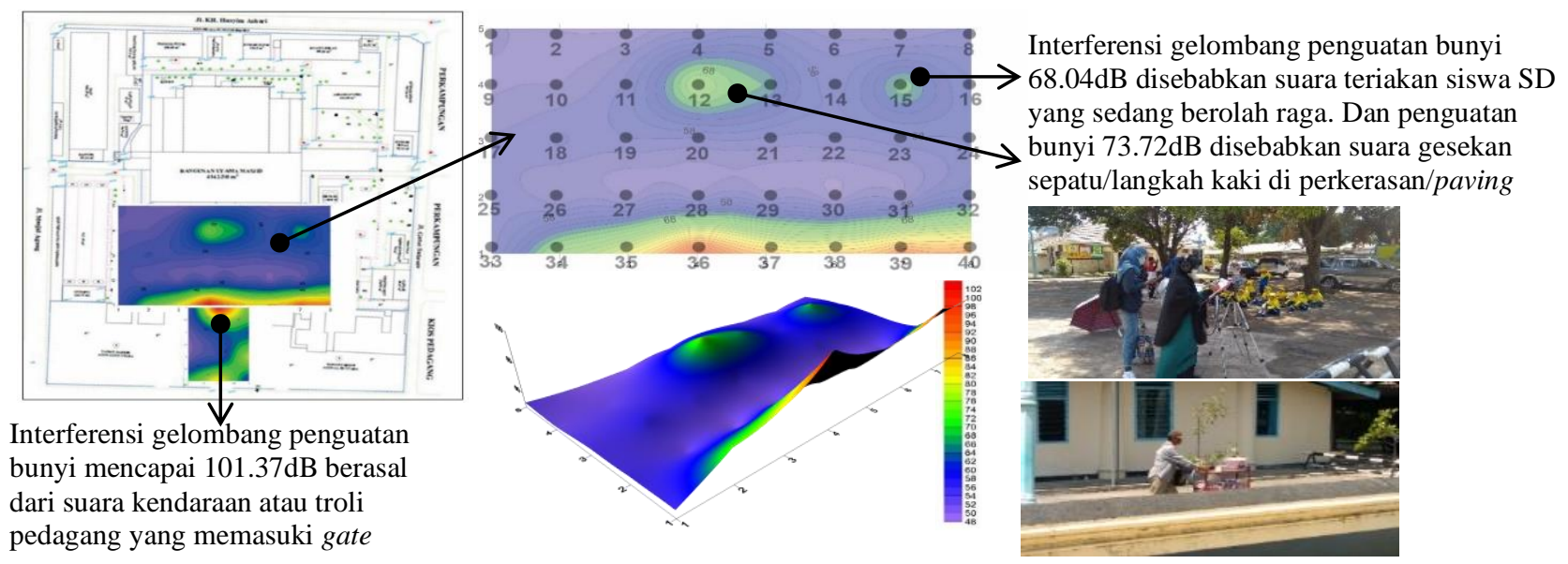

Gambar 6. Hasil Simulasi Dan Analisis Lingkungan Sonik Masjid Agung Surakarta (Pagi-Sore Hari)

Sumber: Analisis Peneliti, 2020 
Karakteristik lingkungan sonik di Masjid Al Wustho dan pengaruh dari kawasan sekitarnya tidak menunjukkan bunyi yang mengganggu, karena rata-rata nilai SPL adalah $63.8 \mathrm{~dB}$, masih dibawah standar bising. Terdapat 3 hasil pengukuran SPL, keadaan pagi, siang dan sore, disebabkan keadaan yang berbeda antara waktu tersebut. Berbeda dengan Masjid Agung yang tidak terdapat perbedaan signifikan hasil pengukuran, antara pagi, siang dan sore. Nilai SPL dapat dilihat dalam tabel 2. Nilai SPL siang dan sore tidak berbeda signifikan. Pagi hari terjadi penguatan bunyi di dua titik yaitu area parkir motor siswa SMA dan pintu masuk halaman masjid. Siang dan sore bunyi terdistribusi merata di halaman tengah, namun intensitas bunyi bertambah tinggi pada posisi dekat dengan jalan raya (siang hari) dan area parkir di halaman masjid (sore hari) (lihat Gambar 7).

Tabel 2. Nilai SPL Masjid Al Wustho

\begin{tabular}{cccccccccccc}
\hline \multicolumn{4}{c}{ Pagi } & \multicolumn{1}{c}{ Siang } & \multicolumn{4}{c}{ Sore } \\
\hline $\begin{array}{c}\text { Titik } \\
\text { Ukur }\end{array}$ & $\begin{array}{c}\text { SPL } \\
(\mathbf{d B})\end{array}$ & $\begin{array}{c}\text { Titik } \\
\text { Ukur }\end{array}$ & $\begin{array}{c}\text { SPL } \\
(\mathbf{d B})\end{array}$ & $\begin{array}{c}\text { Titik } \\
\text { Ukur }\end{array}$ & $\begin{array}{c}\text { SPL } \\
(\mathbf{d B})\end{array}$ & $\begin{array}{c}\text { Titik } \\
\text { Ukur }\end{array}$ & $\begin{array}{c}\text { SPL } \\
(\mathbf{d B})\end{array}$ & $\begin{array}{c}\text { Titik } \\
\text { Ukur }\end{array}$ & $\begin{array}{c}\text { SPL } \\
(\mathbf{d B})\end{array}$ & $\begin{array}{c}\text { Titik } \\
\text { Ukur }\end{array}$ & $\begin{array}{c}\text { SPL } \\
(\mathbf{d B})\end{array}$ \\
\hline 1 & 60.14 & 12 & 64.18 & 1 & 59.33 & 12 & 59.98 & 1 & 58.38 & 12 & 59.98 \\
\hline 2 & 65.88 & 13 & 78.9 & 2 & 60.94 & 13 & 62.17 & 2 & 60.04 & 13 & 62.17 \\
\hline 3 & 63.12 & 14 & 62.41 & 3 & 59.74 & 14 & 65.4 & 3 & 58.71 & 14 & 65.4 \\
\hline 4 & 57.24 & 15 & 62.84 & 4 & 58.76 & 15 & 70.56 & 4 & 61.52 & 15 & 70.56 \\
\hline 5 & 65.86 & 16 & 61.75 & 5 & 60.47 & 16 & 68.51 & 5 & 67.6 & 16 & 68.51 \\
\hline 6 & 64.66 & 17 & 73.78 & 6 & 59.62 & 17 & 67.71 & 6 & 60.88 & 17 & 67.71 \\
\hline 7 & 67.31 & 18 & 68.68 & 7 & 60.31 & 18 & 73.1 & 7 & 65.29 & 18 & 73.1 \\
\hline 8 & 63.33 & 19 & 66.99 & 8 & 58.56 & 19 & 70.5 & 8 & 66.12 & 19 & 70.5 \\
\hline 9 & 64.66 & 20 & 68.11 & 9 & 62.88 & 20 & 71.51 & 9 & 62.88 & 20 & 71.51 \\
\hline 10 & 65.52 & 21 & 63.8 & 10 & 65.13 & 21 & 64.04 & 10 & 65.13 & 21 & 64.04 \\
\hline 11 & 65.52 & & & 11 & 63.3 & & & 11 & 63.3 & & \\
\hline
\end{tabular}

Sumber: Data Pengukuran Lapangan, 2019

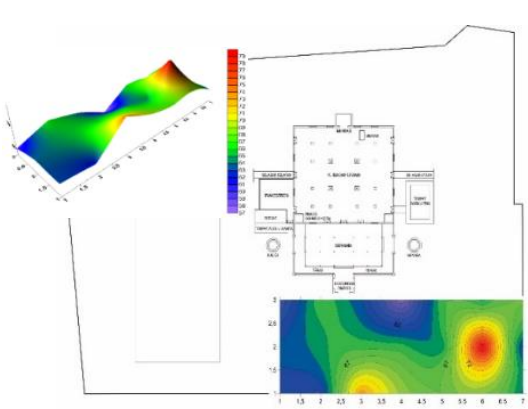

(a)

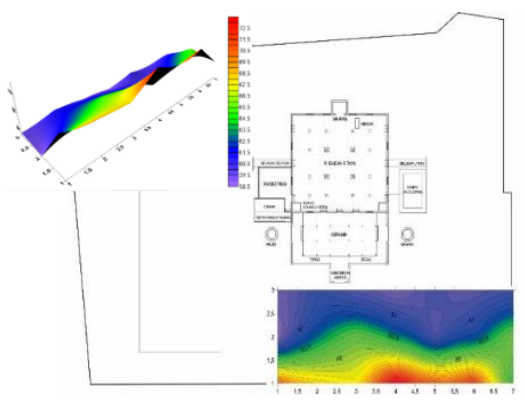

(b)

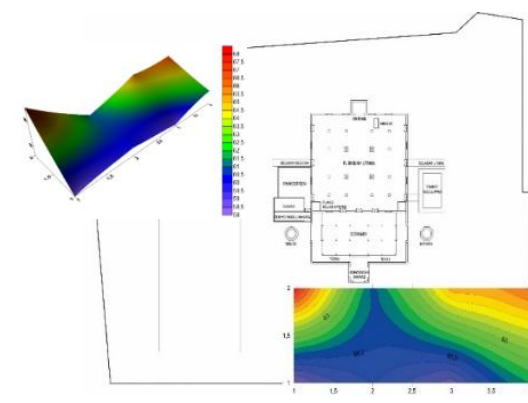

(c)

Gambar 7. Simulasi Pemetaan Iso-Akustik Masjid Al Wustho (a) Pagi Hari, (b) Siang Hari Dan (c) Sore Hari

Sumber: Analisis Peneliti, 2019

Karakter kawasan Masjid Al Wustho adalah karakter kota yang tenang, karena kegiatannya adalah formal, kegiatan pembelajaran yang rutin, tertib dan disiplin. Perkembangan kawasan sekitar Masjid Al Wustho yang dapat dikatakan tetap atau tidak ada perubahan berarti, ternyata tidak menjadikan tata wilayah sakral mendominasi kawasan ini. Pergerakan manusia lebih sedikit bila dibandingkan pergerakan manusia di Masjid Agung, namun ternyata nilai rata-rata SPL Masjid Al Wustho lebih tinggi dari Masjid Agung. Komponen lanskap Masjid Al Wustho terdiri dari paving yang menutupi seluruh halaman masjid, tanaman peneduh dan bangunan terbuka untuk parkir. Proporsi luas halaman masjid dan pergerakan manusia di dalamnya, membentuk karakter lingkungan sonik yang mendekati bising. Terlihat dari hasil pengukuran SPL mencapai nilai tertinggi 78,9 dB. Hal ini 
menandakan bahwa komponen lanskap kurang menyerap bunyi dan atau menyebabkan terjadinya penguatan bunyi. Terlihat dari hasil simulasi (Gambar 7) banyak terdapat interferensi gelombang. Pada pagi hari di titik terdapatnya area parkir, pintu utama dan side entrance masjid yang padat dengan pergerakan siswa SD dan SMA. Pada siang hari penguatan bunyi terjadi di bagian depan halaman masjid yang berbatasan dengan jalan raya. Pada sore hari penguatan bunyi terjadi di bagian side entrance masjid, disebabkan pergerakan siswa SD dan SMA yang hendak keluar dari area parkir. Pada sore hari terjadi penguatan bunyi di sisi timur-selatan masjid, dimana banyak pengunjung terutama orangtua siswa SD yang menjemput anaknya dan menunggu di teras masjid.

\section{Kesimpulan}

Penelitian ini memberikan kebaharuan parameter dalam perencanaan sebuah masjid, terutama pemilihan material lanskap dan pengaturan pergerakan manusia di halaman masjid. Karakter lingkungan sonik masjid sangat tergantung dengan komponen lanskap. Kasus Masjid Agung Surakarta yang berada di kawasan padat dan bising, ternyata memiliki karakter lingkungan sonik yang lebih tenang bila dibandingkan dengan karakter lingkungan sonik di Masjid Al Wustho yang berada di kawasan pendidikan yang sepi dan formil. Komponen lanskap Masjid Agung mendukung tereduksinya kebisingan, yaitu berupa pasir pantai selatan yang terhampar luas di halaman masjid, sedangkan Masjid Al Wustho memiliki komponen lanskap yang justru memperkuat bunyi, yaitu berupa paving dan proporsi luas halaman dengan aktivitas di dalamnya.

Keberlanjutan lingkungan sonik suatu kawasan masjid dan karakter yang dimunculkan, akan dapat dipertahankan ataupun tidak, tergantung dari aktivitas yang terjadi di kawasan tersebut serta komponen lanskap yang ada. Secara umum perkembangan kawasan menjadi lebih padat dan ramai, serta permasalahan kebisingan yang dihasilkan masih dapat diselesaikan. Public space misalnya, yang ramai dan bising, dapat direduksi kebisingannya dengan pengaturan pergerakan aktivitas yang terarah di kawasan tersebut dan penyediaan material landskap yang mampu mereduksi kebisingan, seperti pasir laut pantai selatan, vegetasi dan air.

\section{Ucapan Terima Kasih}

Terima kasih kepada Lembaga Penelitian dan Pengabdian kepada Masyarakat Universitas Muhammadiyah Surakarta, yang telah mendanai penelitian ini dalam skema Penelitian Unggulan Program Studi Arsitektur melalui program ISRECOD 2019.

\section{Daftar Pustaka}

Creswell, J. W. (2007). Perencanaan Penelitian Kualitatif, Kuantitatif dan Mixed (terjemahan). Yogyakarta: Pustaka Pelajar.

D.Zhang, M. D. (2016). Soundscape evaluation in Han Chinese Buddihist temples. Applied Acoustics Vol. 111, 188-197.

Damaranti, N. H. (2017). Karakterisasi Lingkungan Sonik Masjid Multifungsi: Studi Kasus Masjid Gedhe Kauman Yogyakarta. Yogyakarta: Departemen Teknik Nuklir dan Teknik Fisika, Universitas Gadjah Mada.

Egan, D. M. (1988). Architectural Acoustics. New York: Mc Graw-Hill Book Company.

El-Qudsy, Abdul Khaliq Hasan, Priatmoko, Heri, Islam, Syaiful, et.al. (2014). Sejarah Masjid Agung Surakarta. Surakarta: Absolute Media, ISBN: 978-602-7709-87-4, Yogyakarta.

Feby Hendola, R. S. (2018). Peran Elemen Alam pada Sequence Ruang Ibadah, Study Kasus Masjid
Bahrul Ulum Tangerang Selatan. Jurnal Komposisi Vol. 12 No. 2, 129-140.

Fowler, M. D. (2013). Soundscape as a design strategy for landscape architecture praxis. Design Studies Elsevier Vol.34, No. 1, 111-129.

Kang, J. (2010). From understanding to designing soundscape. Frontiers of Architecture and Civil Engineering, 403-417.

Kurniawan, F. A., \& Isranuri, I. (2016). Penyelidikan Karakteristik Mekanik Tarik Paduan Alumunium Magnesium (Al-Mg) dengan Metode Pengecoran Konvesional. Jurnal Inotera Vol. 1 No. 1, 1-4.

Kurtruff, H. (2001). Room Acoustics. London: Taylor \& Francis e-Library, Spon Press.

Lang, J. (1987). Creating Architecture Theory. New York: Van Nostrand Reinhold Con. Inc.

Lusiyana, A., Toifur, M., \& Rohman, F. (2014). Uji Sifat Magnetik Pasir Pantai Melalui Penentuan Permeabilitas Relatif Menggunakan Logger Pro. Jurnal Fisika Vol. 4 No. 2, 78-82. 
Mediastika, C. E. (2005). Akustika Bangunan, Prinsipprinsip dan Penerapannya di Indonesia. Jakarta: Erlangga.

Miller, N. (2013, Volume 3, ISSN 2075-5309). Understanding Soundscape. Buildings, 728-738.

Rehan, R. (2016). The phonic identity of the city urban soundscape for sustainable space. Housing and
Building National Research Center Journal Vol. 12, 337-349.

Schafer, R. M. (1969). Ear Cleaning: Notes for an Experimental Music Course. Canada: Clark \& Cruickshank.

Sugiyono. (2012). Metode Penelitian Kuantitatif, Kualitatif dan $R \& D$. Bandung: Alfabeta. 